\title{
Erratum: Egr-2 and Egr-3 are negative regulators of T cell activation
}

Meredith Safford, Samuel Collins, Michael A Lutz, Amy Allen, Ching-Tai Huang, Jeanne Kowalski, Amanda Blackford, Maureen R Horton, Charles Drake, Ronald H Schwartz \& Jonathan D Powell

Nature Immunology 6, 472-480 (2005).

On page 476, the top panel of Figure $5 \mathrm{c}$ was incorrect. The correct figure is provided here.
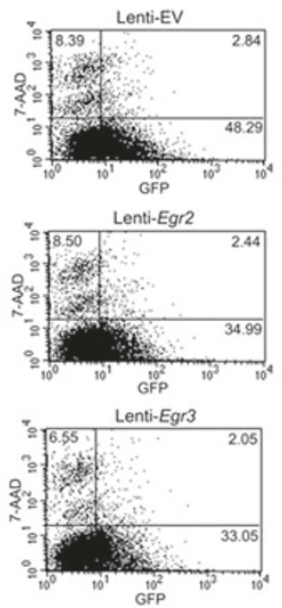